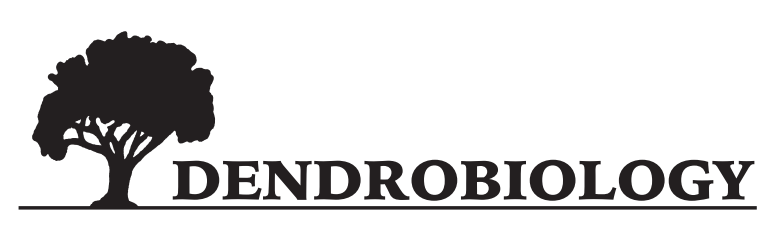

2019, vol. 81, 47-57

http://dx.doi.org/10.12657/denbio.081.006

\author{
Marek Szymajda, Edward Żurawicz, Robert Maciorowski, Kris Pruski
}

\title{
Stratification period combined with mechanical treatments increase Prunus persica and Prunus armeniaca seed germination
}

Received: 4 February 2019; Accepted: 18 June 2019

\begin{abstract}
The deep dormancy of the Prunus species seeds is caused by the presence of germination inhibitors, mainly abscisic acid (ABA) - in the endocarp, the seed coat and endosperm, and in the embryo. As a consequence, the removal of the endocarp, the seed coat together with the endosperm increases the number of germinated seeds. The effect of different treatments of seeds of three peach cultivars - 'Madison', 'Elberta' and 'Rakoniewicka', and of three apricot cultivars - M II-42, 'Bella' and 'Somo', were assessed in terms of seed germination and the growth of obtained young seedlings. Seed treatments involved different duration of stratification period at $5^{\circ} \mathrm{C}$ and removing endocarp, seed coat with endosperm and the part of cotyledons of the embryo. The best seed/embryo germination, about $96 \%$ for the peach cultivars and practically $100 \%$ for the apricot cultivars, was obtained by stratifying seeds for 90 days and then removing the seed coat together with the endosperm and subjecting the extracted embryos to a temperature of $20^{\circ} \mathrm{C}$. The seedlings obtained from the seeds treated this way have shown good growth. Using these treatments, it was possible to obtain a larger number of apricot and peach seedlings, and thus increase the breeding efficiency of these species.
\end{abstract}

Keywords: peach and apricot embryo, cotyledon shortening, young seedlings growth, survival analysis, Kaplan-Meier estimator

Addresses: M. Szymajda, E. Żurawicz, R. Maciorowski, Research Institute of Horticulture, Konstytucji 3 Maja 1/3, 96-100 Skierniewice, Poland, e-mail: marek.szymajda@inhort.pl

K. Pruski, Department of Plant, Food, and Environmental Sciences, Dalhousie University, PO Box 550, Truro, NS, B2N 5E3

\section{Introduction}

The deep dormancy of seeds of the Prunus species is caused by the presence of germination inhibitors, mainly abscisic acid (ABA), at various concentrations in various parts of the stone and seeds - in the endocarp, the seed coat and endosperm which is the thin layer surrounds the embryo, and in the embryo (Chen et al., 2007; Jensen \& Kristiansen, 2009; San et al., 2014).
The endocarp, in addition to protecting the seed, also provides a mechanical barrier during germination hindering the access of water to the seed inside endocarp (Du Toit et al., 1979) as well as the leaching of germination inhibitors from the seed coat and the embryo (Jensen \& Kristiansen, 2009). The endocarp itself is also a source of germination inhibitors, the concentration of which decreases during stratification (Chen et al., 2007). As a consequence, the removal of the endocarp reduces the time required for 
stratification and increases the number of germinated seeds in many species of woody plants, including peach, sour cherry, sweet cherry and Mahaleb cherry (Zielinski, 1958; Suszka, 1964; Mehanna \& Martin, 1985; Jakubowski, 2000; Martínez-Gómez \& Dicenta, 2001; Jensen \& Kristiansen, 2009; Ghayyad et al., 2010).

The inhibitors contained in the seed coat and the endosperm prevent the growth of the radicle in seeds of the genus Prunus. The removal of the seed coat together with the endosperm allows the seeds of peach (Mehanna \& Martin, 1985; Martínez-Gómez \& Dicenta, 2001), sweet cherry (Zielinski, 1958; Michalska, 1982) and sour cherry (Jensen \& Kristiansen, 2009) to germinate within a dozen or so days without the need to subject them to stratification. However, the upper part of the embryonic axis of germinated seeds that have not been subjected to chilling shows developmental disorders. The seedlings obtained in this way are characterized by greatly shortened internodes of the stem and severely stunted growth, although their root system develops normally (Flemion, 1933; 1934).

Growth inhibition of the apical part of the embryonic axis in non-stratified seeds is caused by the presence of growth inhibitors contained in the cotyledons (Flemion, 1965; Jensen \& Kristiansen, 2009). Therefore, shortening of the cotyledons of peach embryos makes it possible to obtain normal growth of seedlings, even without prior chilling of seeds (Flemion, 1965). These observations were confirmed by Danish researchers (Jensen \& Kristiansen, 2009) who, by shortening the cotyledons of sour cherry embryos, obtained normally growing seedlings within a few weeks after planting the modified embryos.

It is a well-known fact that the deep dormancy of Prunus seeds is broken during their post-harvest maturation while being subjected to stratification (Suszka, 1967; Mehanna \& Martin, 1985; Martínez-Gómez \& Dicenta, 2001; Jensen \& Kristiansen, 2009; Seliga \& Żurawicz, 2011; Szymajda, et al., 2011; Szymajda, et al., 2013; Szymajda \& Zurawicz, 2014), under the influence of low temperature, causing the decomposition of germination inhibitors (Chen et al., 2007). It is often the case, however, that even after long-lasting, stratification, not all of the stratified seeds germinate. A low seed germination percentage is a major problem, especially in the stone fruit breeding, such as in peach and/or apricot. The fruits of these species contain only one stone, in which there is usually only one, often not fully developed seed. For this reason, in peach and apricot crossbreeding programs, very few seeds and seedlings of both species are obtained in relation to the number of pollinated flowers. These factors make the applied breeding of these species low efficient. Consequently, research is being undertaken on the possibility of obtaining uniform germination of seeds through the efficient breaking of their dormancy.

The aim of the study was to assess the possibility of increasing number of germinated peach and apricot seeds by combining different durations of stratification with mechanical removal of the endocarps, the seed coat with endosperm and the parts of the embryo cotyledons to increase the breeding efficiency of the species.

\section{Material and methods}

\section{Research material}

The objects studied were seeds of three peach cultivars - 'Madison', 'Elberta' and 'Rakoniewicka', and three apricot cultivars - M II-42, 'Bella' and 'Somo'. These cultivars are well known in Poland, they differ in fruit ripening time and are well adapted to the local climatic conditions. There were three series of tests, which were carried out at the turn of the years 2013/2014, 2014/2015 and 2015/2016 at the Research Institute of Horticulture in Skierniewice, Poland. In Poland, the tested peach cultivars are characterized by late fruit ripening, which falls around mid-September. By contrast, the tested apricot cultivars are characterized by different times of fruit ripening. The fruit of the M II-42 variety mature around the middle of July, those of the cultivar 'Bella' at the end of July/beginning of August, and those of 'Somo' around the middle of August. The seeds for testing were obtained from trees that grew in the cultivar collection lot of the Experimental Orchard of the Research Institute of Horticulture in Dąbrowice near Skierniewice (Central Poland, at 145 m altitude, $\left.51^{\circ} 54^{\prime} \mathrm{N} / 20^{\circ} 06^{\prime} \mathrm{E}\right)$. The seeds were collected successively as the fruits matured, at the stage of their harvest maturity. For each cultivar, the fruits from which stones were to be obtained were collected randomly from three trees, 300-400 fruits from each tree, from a height of 1.0-1.8 m. The stones extracted from the fruit were cleaned of the remaining flesh, dried at room temperature of about $20^{\circ} \mathrm{C}$, and stored in paper bags under the same conditions for 3-6 months until testing.

\section{Experimental treatments}

For each genotype, 10 experimental treatments were applied, nine of which involved stratification of seeds or embryos (Fig. 1). Before stratification, the endocarp was removed mechanically from the stones by a vice and the seed was extracted (except the control treatment). Poorly developed seeds were eliminated from the tests. The obtained seeds were disinfected by soaking for 24 hours in a $0.1 \%$ solution 


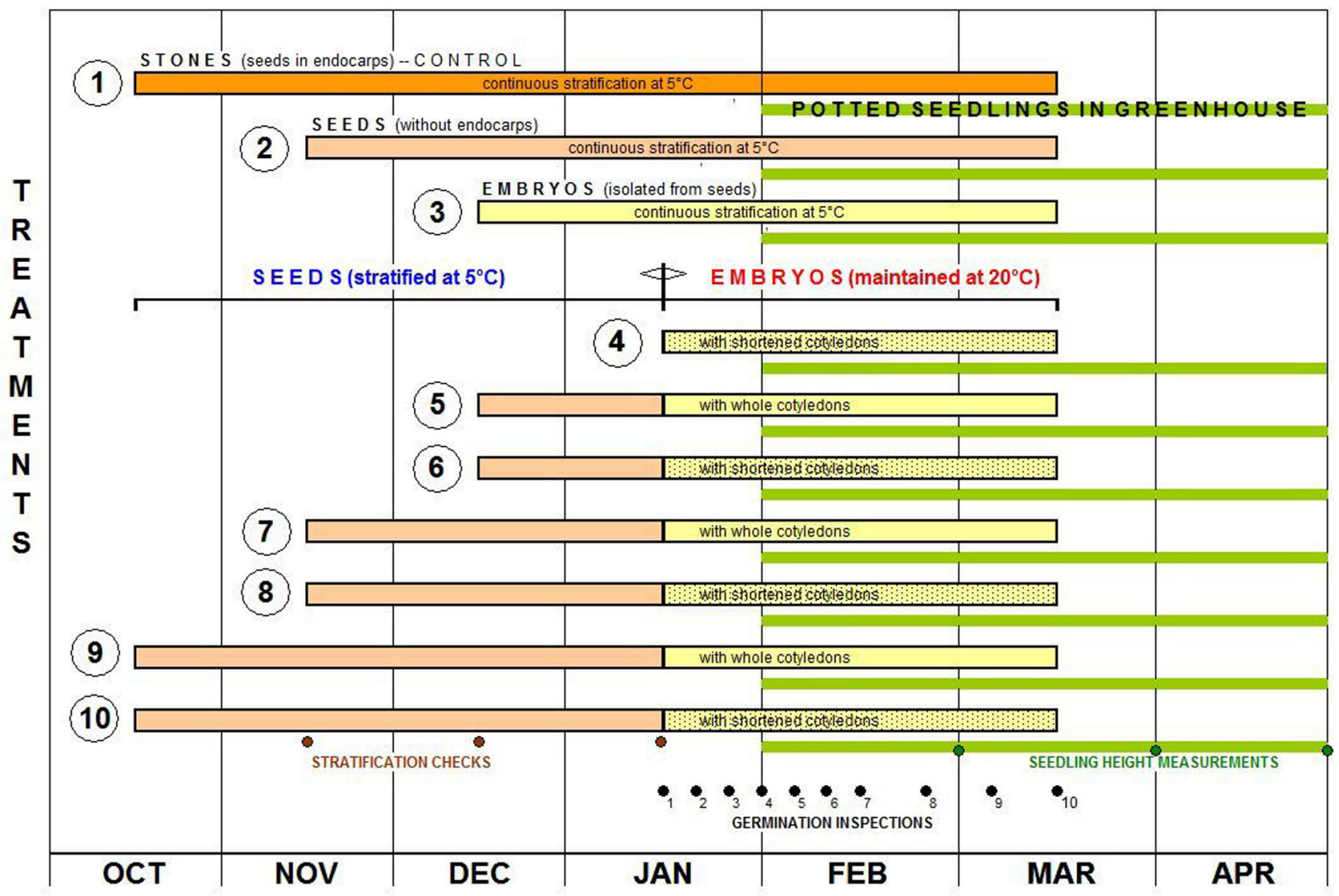

Fig. 1. Experimental treatments 1-10 shown on a time scale. $\uparrow$ - date of placing of bags with embryos (treatments 4-10) at a room temperature of $20^{\circ} \mathrm{C}, 0$ - date of stratification check, - date of germination inspection, $\mathrm{O}$ - date of seedling height measurement, - stratification period at a temperature of $5^{\circ} \mathrm{C}$ (treatments $1-3$, continuous stratification), - maintenance period of embryos at a room temperature of $20^{\circ} \mathrm{C}$ (treatments $4-10$ ), growth in greenhouse

of Captan 50 WP suspension fungicide (50\% captan, Arysta Life Science North America Co., San Francisco, USA). Next, the seeds/embryos were mixed with sterile and moist perlite (volume ratio of 1:3 one part stones to four parts perlite), packed into plastic bags and subjected to stratification at $5^{\circ} \mathrm{C}$ in a MIR-554 chilling incubator (SANYO, Moriguchi, Osaka Prefecture, Japan). Different durations of stratification were applied, as shown graphically on a time scale in Fig. 1. Inspections were conducted after 30,60 and 90 days of stratification, during which soil moisture was sensory checked and the seeds were aerated. Each experimental treatment involved 20 stones or seeds/embryos in 3 replications.

The control treatment involved stratification of stones (seeds with endocarps). Before stratification, the stones were also disinfected by soaking for 24 hours in a $0.1 \%$ solution of Captan 50 WP suspension fungicide. Stones floating on the surface of the solution after 24 hours of disinfection were considered as not containing fully developed seeds and were eliminated from the tests.

After the completion of stratification, on January 15 of every year, the seed coat and the endosperm were removed from the seeds in Treatments 5-10 to isolate the embryos. In addition, the cotyledons of embryos in Treatments 6,8 and 10 were shortened by two-thirds of their length. In Treatment 4 (non-stratified seeds), after 24 hours of disinfection in a $0.1 \%$ solution of Captan 50 WP suspension fungicide, the seed coat and endosperm were removed from the seeds. Then, as in Treatments 6, 8 and 10, the cotyledons of those embryos were shortened by removing two-thirds.

Whole embryos and embryos with shortened cotyledons prepared in this way (Treatments 4-10) were again disinfected for $30 \mathrm{~min}$. in a $0.1 \%$ solution of Captan 50 WP suspension fungicide, mixed with moist sterile perlite and packed into plastic bags. The substrate was also moistened with a $0.1 \%$ solution of Captan 50 WP suspension fungicide. The bags with embryos were placed at a room temperature of $20^{\circ} \mathrm{C}$ and protected from light. In Treatments $1-3$, chilling stratification of stones (Treatment 1), seeds (Treatment 2) and embryos (Treatment 3 ) continued uninterrupted at $5^{\circ} \mathrm{C}$.

Inspections of stones and seeds/embryos in all treatments began on January 15 . The first 7 
inspections were carried out at 5-day intervals, and the next three every 10 days, with the last inspection carried out 60 days after the first inspection. During the inspections, the germinating seeds/embryos were selected and counted. Seeds/embryos with a growing $6-15 \mathrm{~mm}$ long radicle were considered as having germinated. In the control treatment, after 150 days of stratification, endocarps were removed from ungerminated seeds (stones), and the number of well-developed seeds was counted. The percentage of germinated seeds in that experimental treatment was calculated from the number of fully developed (viable) seeds.

\section{Growth of young seedlings}

Germinating seeds/embryos (with a 6-15 mm long radicle) were planted out into $350 \mathrm{~cm}^{3}$ plastic pots filled with a sterile substrate consisting of a $3: 1$ $\mathrm{v} / \mathrm{v}$ mixture of peat and washed sand (Fig. 2). In order to be able to compare the growth of seedlings of all the experimental treatments, the germinated seeds and embryos obtained during the first three inspections were kept in plastic bags filled with moist perlite in a refrigerator at $3^{\circ} \mathrm{C}$ until January 30 . Subsequently, these seeds/embryos, together with those that had germinated between January 25 and 30 (4th inspection), were planted out into pots. The seeds/ embryos that had germinated by February 9 (5th and 6th inspection) were also taken for further testing. In this way, in each year of testing, all of the seeds/ embryos were planted out at a similar time, i.e. from January 30 to February 9.

The pots with germinated seeds/embryos were placed in a heated greenhouse $\left(20 / 16^{\circ} \mathrm{C}\right.$ day/night) equipped with a system of artificial lighting (16/8 h day/night), where the growing seedlings remained until the end of April. When planted out into pots, the seeds/embryos were watered twice with a $0.1 \%$ solution of Aliette 80 WP fungicide (80\% fosetyl-Al). The first watering was done immediately after planting, and the second 5 days later.

Each experimental treatment involved 30 seedlings - three replications of 10 seedlings each, except

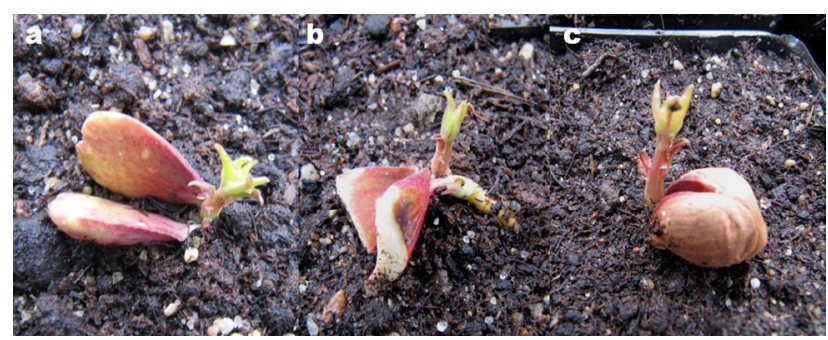

Fig. 2. Young apricot seedlings growing from embryos planted out into pots in a greenhouse: a) from an embryo with whole cotyledons, b) from an embryo with shortened cotyledons, c) from a seed with the seed coat for the treatments where too few seeds had germinated. These were the seedlings of the peach cultivars 'Madison'- Treatments 1-3 (3-9, 15-21, 15-21 seedlings, respectively), 'Elberta' - Treatments 1-3 (3-9, 12-27 and 21-27 seedlings, respectively), and 'Rakoniewicka' - Treatments 1-3 (9-21, 12-24 and 12-21 seedlings, respectively), and the seedlings of the apricot cultivar 'Somo' - Treatment 3 (12-15 seedlings). The experiment was arranged in a completely randomized design. For each treatment, the height of seedlings was measured after 30, 60 and 90 days of their growth in the greenhouse.

\section{Statistical analysis}

Due to the high amount of ungerminated seeds at the end of the monitoring period and seeds/embryos lost over the duration of the experiment (right-censored data), particularly in the control variant (Treatment 1), the data over time were analyzed by means of the semi-parametric Cox proportional hazards model. This method was created to analyze exact data (continuous data over time). Our experimental data did not have a continuous structure because the numbers of germinated seed/embryos were counted at 5-day intervals (the first 7 inspections) followed by 10-day intervals (the last three inspections). MacNair et al. (2012) suggest that using this method of analyzing such germination data is safe and appropriate. The proportional hazard assumption of the Cox model was verified by means of the graphical method using Kaplan-Meier estimates of the survivor function and applying the proportional hazard test developed by Therneau and Grambsch (2000). The model was built with year $(\mathrm{Y})$, genotype $(\mathrm{G})$, seed/embryo treatment $(\mathrm{T})$, and their interactions as covariates, separately for the two fruit species. The significance of the models produced and of the covariates in the models was tested by the Wald test. The Kaplan-Meier survivor functions for each seed treatment were compared using the Peto-Peto test at $\mathrm{p}=0.05$ with Holm-Bonferroni adjustment for multiple comparisons.

Seedling growth data was analyzed using a repeated-measures ANOVA. The repeated-measure factor was the time of measurement, with year, genotype, treatment and their interactions being the other effects in the analysis. Prior to analysis, all data were Box-Cox transformed. Normality was confirmed, and homogeneity of variance verified with Levene's test. The sphericity assumption was evaluated with Mauchly's test. If sphericity was violated, adjustments were performed with the Greenhouse-Geisser correction. Post hoc comparisons were made with Tukey's HSD test at $\mathrm{p}=0.05$.

All calculations were performed using STATISTICA v. 11 package (Dell Inc., 2016). 


\section{Results}

\section{Seed germination}

The course of seed germination, in both species, was the most affected by the method of treating the seeds/embryos, i.e. the duration of the stratification period and by removing the endocarp, seed coat and endosperm, and the part of cotyledons of embryos (Table 1). The results are shown in Figs 3 and 4 by the survivor function, which represents the probability of non-germination of seeds over time. Despite the long stratification period of 150 days, the final (day 60) germination percentage of seeds (stones) of 'Madison', 'Elberta' and 'Rakoniewicka' peaches in the control treatment, estimated from the survivor function, was $8.0 \%, 8.4 \%$ and $53.9 \%$, respectively (Fig. 3). The removal of the sources of germination inhibitors resulted in an increase in the number of germinated seeds/embryos in the cultivar 'Madison'

Table 1. Results of statistical significance of the tested covariates of the Cox proportional hazard model for peach and apricot

\begin{tabular}{lrrrrr}
\hline \multirow{2}{*}{$\begin{array}{c}\text { Treatment } \\
\text { (covariate } x_{i} \text { ) }\end{array}$} & df & Wald & Peach & Wald & Apricot \\
\cline { 3 - 6 } & & 21.1 & $<0.001$ & 3.2 & 0.202 \\
Year (Y) & 2 & 6.8 & 0.034 & 2.8 & 0.247 \\
Genotype (G) & 2 & 125.2 & $<0.001$ & 134.3 & $<0.001$ \\
Seed Treatment (T) & 9 & 6.7 & 0.150 & 2.8 & 0.592 \\
$\mathrm{Y} \times \mathrm{G}$ & 4 & 53.1 & $<0.001$ & 42.1 & $<0.001$ \\
$\mathrm{G} \times \mathrm{T}$ & 18 & 35.4 & $<0.001$ & 38.4 & $<0.001$ \\
$\mathrm{Y} \times \mathrm{T}$ & 18 & 42.1 & $<0.001$ & 39.2 & $<0.001$ \\
$\mathrm{Y} \times \mathrm{G} \times \mathrm{T}$ & 36 & & &
\end{tabular}

Wald statistic for the model - 1276.6; $<<0.001 \quad$ Wald statistic for the model $-1611.6 ; \mathrm{p}<0.001$

$d f$ - degree of freedom; $p$ - probability of statistic; Wald - statistic for significance testing of the covariates of the hazard function and for the whole model significance testing.
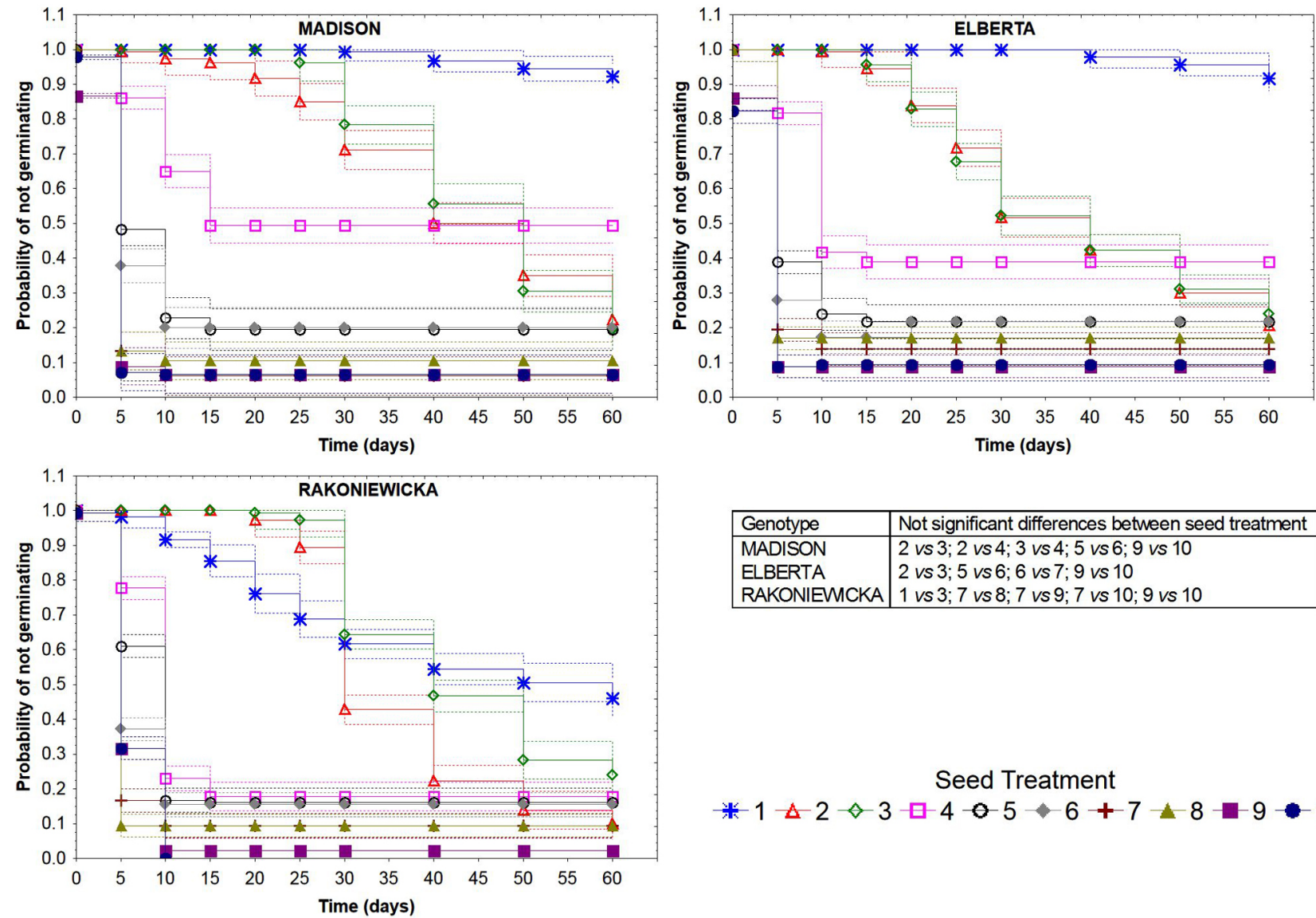

\begin{tabular}{|l|l|}
\hline Genotype & Not significant differences between seed treatment \\
\hline MADISON & 2 vs $3 ; 2$ vs $4 ; 3$ vs $4 ; 5$ vs $6 ; 9$ vs 10 \\
ELBERTA & 2 vs $3 ; 5$ vs $6 ; 6$ vs $7 ; 9$ vs 10 \\
RAKONIEMMKA & 1 vs $3 ; 7$ vs $8 ; 7$ vs $9 ; 7$ vs $10 ; 9$ vs 10 \\
\hline
\end{tabular}

\section{Seed Treatment}

$+1-2 \diamond 3-4-0-5-6+7-8-9-10$

Fig. 3. Kaplan-Meier estimates of the survivor function and $95 \%$ confidence intervals (doted lines) of germinating seeds of the tested peach genotypes depending on seed treatment. In the table: results of seed treatment comparisons using the Peto-Peto test at $\mathrm{p}=0.05$ adjusted for multiple comparisons by means of the Holm-Bonferroni method 
to $93.0 \%$ (Treatment 9), in 'Elberta' to $90.6 \%$ (Treatment 10), and in the cultivar 'Rakoniewicka' to $100 \%$ (Treatment 10). By comparison, the seed/embryo germination percentage for apricot cultivars 'Bella', 'M II-42' and 'Somo' in the control treatment was $90.0 \%, 93.9 \%$ and $91.1 \%$, respectively (Fig. 4). After removing the sources of inhibitors, seed/embryo germination increased in cultivar 'Bella' to $96.7 \%$ (Treatment 10), in M II-42 to $99.4 \%$ (Treatments 9 and 10), and in 'Somo' to $100 \%$ (Treatments 9 and 10). It should be emphasized that in both species there were no significant differences in the germination percentage between treatments 9 and 10 .

The removal of the endocarp and the seed coat with endosperm not only increased the number of germinated seeds but also reduced the duration of stratification required to break their dormancy. The first germinated peach seeds in the control treatment were obtained after 100 days of stratification - 3rd inspection (after 10 days at $20^{\circ} \mathrm{C}$ ) (Fig. 3). Seeds without the endocarp (Treatment 2) germinated after 65 days -2 nd inspection (after 5 days), whereas extracted embryos (Treatment 3 ) after 45 days -4 th inspection (after 15 days). A similar correlation occurred in apricot (Fig. 4).
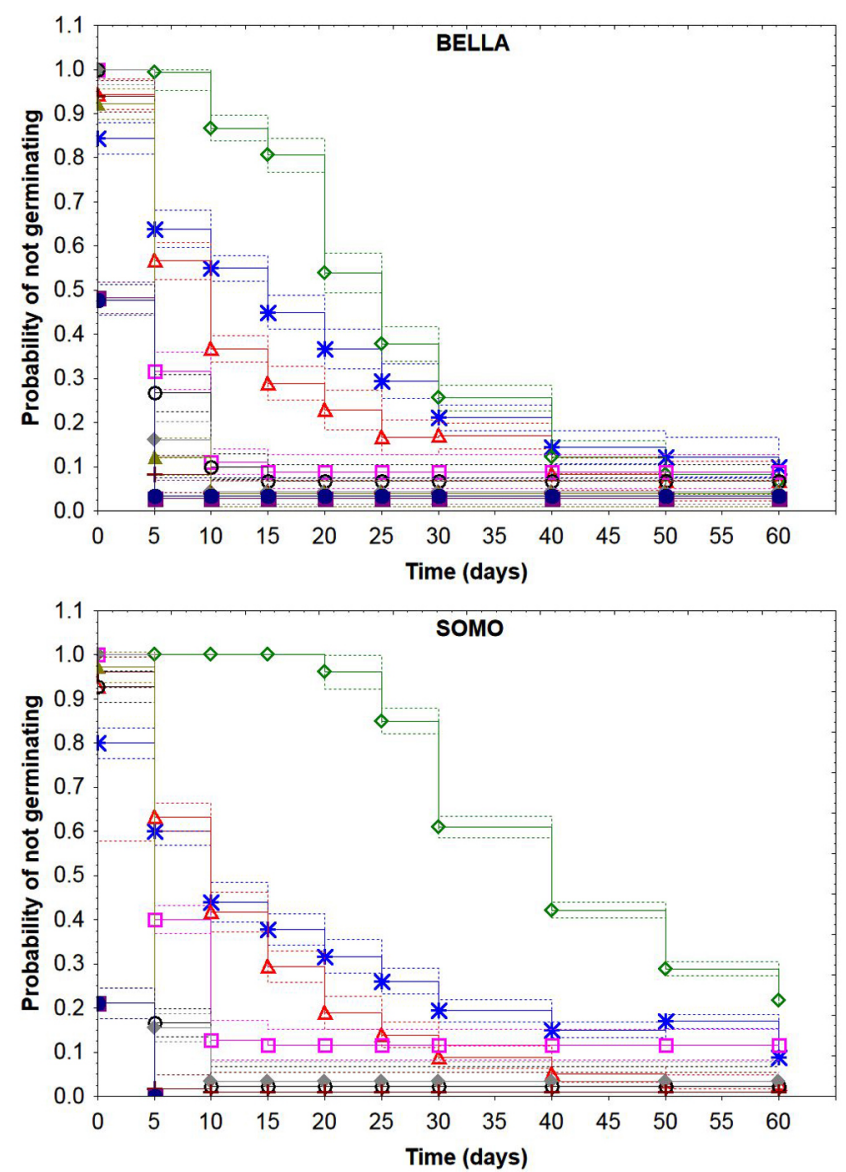

Undoubtedly, an important factor having a positive effect on the germination of extracted embryos was the removal of two-thirds of their cotyledons (Fig. 3 and 4). Except for the apricot cultivar 'Somo', among the seeds of both species stratified for 30 days, it was observed that after 5 days at $20^{\circ} \mathrm{C}$ more embryos with shortened cotyledons (Treatment 6) had germinated than embryos with the cotyledons left intact (Treatment 5). However, the observed differences were not significant and became less pronounced with the passage of time.

As shown by the results of our study, the germination percentage of peach and apricot seeds and embryos increased with the duration of stratification, although this was more evident in the case of peach seeds. This correlation was clearly apparent in both the seeds subjected to continuous stratification at $5^{\circ} \mathrm{C}$ (Treatments 1-3) and the seeds which had been stratified at this temperature for 30, 60 and 90 days and then had the sources of inhibitors removed and were transferred to $20^{\circ} \mathrm{C}$ (Treatments 5-10). After 5 days of keeping seeds at $20^{\circ} \mathrm{C}$, the lowest germination was observed in the non-stratified embryos.

Table 2 presents summary models of the hazard function estimating the impact of the individual

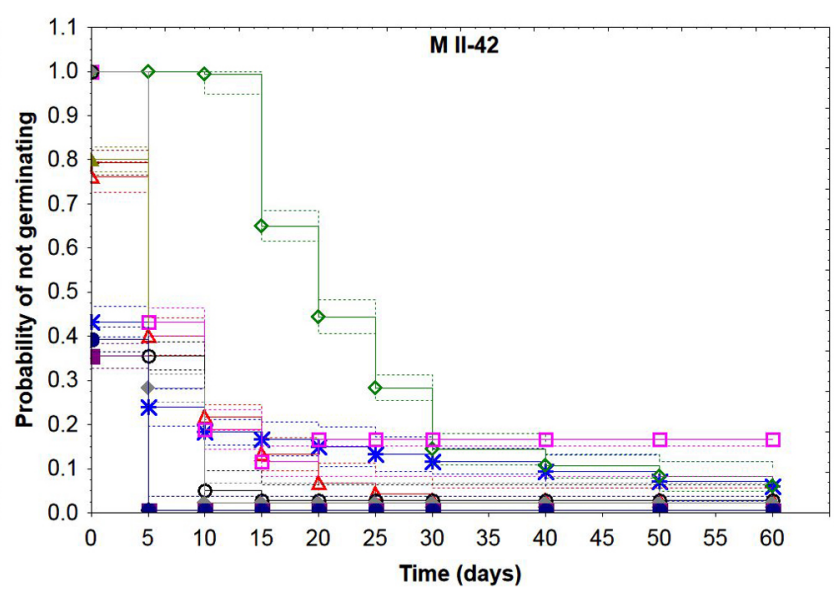

\begin{tabular}{|l|l|}
\hline Genotype & Not significant differences between seed treatment \\
\hline BELLA & 1 vs $2 ; 4$ vs $5 ; 5$ vs $6 ; 6$ vs $8 ; 7$ vs $8 ; 9$ vs 10 \\
M II-42 & 2 vs $5 ; 2$ vs $6 ; 4$ vs $5 ; 5$ vs $6 ; 7$ vs $8 ; 9$ vs 10 \\
SOMO & 1 vs $2 ; 1$ vs $4 ; 5$ vs $6 ; 7$ vs $8 ; 9$ vs 10 \\
\hline
\end{tabular}

Seed Treatment

$*-1 \Delta 2 \diamond 3-4-0-5-6+7-8-9-10$

Fig. 4. Kaplan-Meier estimates of the survivor function and 95\% confidence intervals (doted lines) of germinating seeds of the tested apricot genotypes depending on the seed treatment. In the table: results of the seed treatment comparisons using the Peto-Peto test at $\mathrm{p}=0.05$ adjusted for multiple comparisons by means of the Holm-Bonferroni method 
Table 2. Results of the Cox proportional hazard model for peach and apricot genotypes describing seed germination depending on treatment. The control treatment was treated as a reference variant

\begin{tabular}{|c|c|c|c|c|c|c|c|c|c|c|c|c|}
\hline \multirow{3}{*}{$\begin{array}{l}\text { Treatment } \\
\text { (covariate } x_{i} \text { ) }\end{array}$} & \multicolumn{12}{|c|}{ Peach } \\
\hline & \multicolumn{4}{|c|}{ Madison } & \multicolumn{4}{|c|}{ Elberta } & \multicolumn{4}{|c|}{ Rakoniewicka } \\
\hline & $\beta i$ & $\exp (\beta i)$ & $\chi^{2}$ & $\mathrm{P}$ & $\beta i$ & $\exp (\beta i)$ & $\chi^{2}$ & $\mathrm{P}$ & $\beta i$ & $\exp (\beta i)$ & $\chi^{2}$ & $\mathrm{P}$ \\
\hline 2 & 2.52 & 12.4 & 80.7 & $<0.001$ & 2.45 & 11.6 & 81.5 & $<0.001$ & 0.54 & 1.7 & 17.3 & $<0.001$ \\
\hline 3 & 2.53 & 12.5 & 81.6 & $<0.001$ & 2.42 & 11.2 & 78.8 & $<0.001$ & 0.27 & 1.3 & 4.3 & 0.039 \\
\hline 4 & 2.23 & 9.3 & 60.2 & $<0.001$ & 2.41 & 11.2 & 76.8 & $<0.001$ & 0.96 & 2.6 & 53.4 & $<0.001$ \\
\hline 5 & 3.24 & 25.5 & 133.5 & $<0.001$ & 2.91 & 18.3 & 114.0 & $<0.001$ & 1.09 & 3.0 & 68.8 & $<0.001$ \\
\hline 6 & 3.31 & 27.4 & 139.5 & $<0.001$ & 3.04 & 21.0 & 125.3 & $<0.001$ & 1.23 & 3.4 & 88.0 & $<0.001$ \\
\hline 7 & 3.98 & 53.9 & 203.5 & $<0.001$ & 3.15 & 23.3 & 134.2 & $<0.001$ & 1.55 & 4.7 & 140.6 & $<0.001$ \\
\hline 8 & 3.83 & 46.1 & 187.8 & $<0.001$ & 3.23 & 25.2 & 141.0 & $<0.001$ & 1.60 & 5.0 & 150.0 & $<0.001$ \\
\hline 9 & 4.12 & 61.7 & 217.6 & $<0.001$ & 3.42 & 30.6 & 158.7 & $<0.001$ & 1.68 & 5.4 & 166.1 & $<0.001$ \\
\hline 10 & 4.06 & 58.2 & 211.4 & $<0.001$ & 3.44 & 31.2 & 160.5 & $<0.001$ & 1.75 & 5.8 & 180.4 & $<0.001$ \\
\hline
\end{tabular}

\begin{tabular}{|c|c|c|c|c|c|c|c|c|c|c|c|c|}
\hline \multirow{3}{*}{$\begin{array}{l}\text { Treatment } \\
\left(\text { covariate } x_{i}\right)\end{array}$} & \multicolumn{12}{|c|}{ Apricot } \\
\hline & \multicolumn{4}{|c|}{ Bella } & \multicolumn{4}{|c|}{ M II-42 } & \multicolumn{4}{|c|}{ Somo } \\
\hline & $\beta i$ & $\exp (\beta i)$ & $\chi^{2}$ & $\mathrm{P}$ & $\beta i$ & $\exp (\beta i)$ & $\chi^{2}$ & $\mathrm{P}$ & $\beta i$ & $\exp (\beta i)$ & $\chi^{2}$ & $\mathrm{P}$ \\
\hline 2 & 0.21 & 1.2 & 3.7 & 0.054 & -0.17 & 0.8 & 2.4 & 0.120 & 0.18 & 1.2 & 2.8 & 0.094 \\
\hline 3 & -0.26 & 0.8 & 5.6 & 0.018 & -0.95 & 0.4 & 75.6 & $<0.001$ & -0.84 & 0.4 & 52.3 & $<0.001$ \\
\hline 4 & 0.36 & 1.4 & 10.4 & 0.001 & -0.46 & 0.6 & 16.8 & $<0.001$ & 0.20 & 1.2 & 3.1 & 0.077 \\
\hline 5 & 0.44 & 1.6 & 15.6 & $<0.001$ & -0.16 & 0.9 & 2.0 & 0.154 & 0.66 & 1.9 & 34.3 & $<0.001$ \\
\hline 6 & 0.56 & 1.8 & 24.9 & $<0.001$ & -0.09 & 0.9 & 0.6 & 0.425 & 0.62 & 1.7 & 30.6 & $<0.001$ \\
\hline 7 & 0.66 & 1.9 & 34.5 & $<0.001$ & 0.35 & 1.4 & 9.8 & 0.002 & 0.85 & 2.3 & 53.9 & $<0.001$ \\
\hline 8 & 0.65 & 1.9 & 33.8 & $<0.001$ & 0.35 & 1.4 & 9.8 & 0.002 & 0.90 & 2.5 & 59.7 & $<0.001$ \\
\hline 9 & 1.18 & 3.3 & 109.9 & $<0.001$ & 0.81 & 2.2 & 52.3 & $<0.001$ & 1.93 & 6.9 & 266.0 & $<0.001$ \\
\hline 10 & 1.16 & 3.2 & 106.1 & $<0.001$ & 0.76 & 2.1 & 45.7 & $<0.001$ & 1.93 & 6.9 & 266.0 & $<0.001$ \\
\hline
\end{tabular}

$\beta i$-slope coefficient for the $i$-th covariate, $\exp (\beta i)$ - hazard ratio (a value less than " 1 " means that the hazard function is less than that of the reference variant and a value greater than ' 1 ' means that the hazard function is higher than that of the reference variant, i.e. that the seeds of this variant will germinate earlier), $\chi^{2}$ - value of chi-square test statistic for significance testing of the $i$-th covariate, $P$ - probability of the statistic.

methods of treating seeds/embryos, as compared with the control treatment, on the germination of seeds/embryos of individual peach and apricot cultivars. It can be seen that in the case of peach, for all the treatments of seeds, positive regression coefficients $(\beta i)$ were obtained and, therefore, hazard ratios $[\exp (\beta i)]$ greater than 1 . This means that each of the applied seed/embryo treatment methods increased the probability of seed germination in relation to the control treatment. Treatments 9 and 10 increased the probability of seeds germinating 60 times in the cultivar 'Madison', 30 times in 'Elberta', and 5 times in 'Rakoniewicka'. The situation was more varied in apricot. Treatment 3 in all the apricot cultivars, and additionally Treatments 2, 4, 5 and 6 in the cultivar M II-42, had a similar effect on the course of germination compared with that of the control combination. It should be emphasized, however, that the best methods of treating seeds/ embryos were Treatments 9 and 10, whose impact on germination measured by the hazard ratio, in relation to the control treatment, was smaller than in the case of peach (2.2 for 'M II-42', 3.3 for 'Bella', and 6.9 for 'Somo').

\section{Growth of young seedlings}

All the experimental factors and their interactions in the linear model of ANOVA proved to be significant. The tallest peach seedlings were obtained from the seeds stratified for at least 60 days (Fig. 5). Seedlings obtained from embryos with whole cotyledons, extracted from seeds stratified for 60 or 90 days (Treatments 7 and 9), were taller than the seedlings obtained from embryos exposed to chilling for 30 days (Treatment 5). Tall apricot seedlings were also obtained in treatments no. 1 and 2 (Fig. 6). With the exception of cv. 'Somo' apricot seedlings, these differences were statistically significant in relation to the seedlings in the treatments no. 5. Despite germinating of non-stratified embryos, the resulting seedlings did not grow normally. They had significantly shortened internodes and exhibited stunted growth (rosette). Normally growing seedlings were obtained from seeds stratified for at least 30 days.

Shortening the cotyledons resulted in the weakening of the growth of obtained seedlings. These seedlings were always shorter than the seedlings obtained from embryos with whole cotyledons, stratified for the same length of time. This correlation was most evident in the first month of seedling growth. 

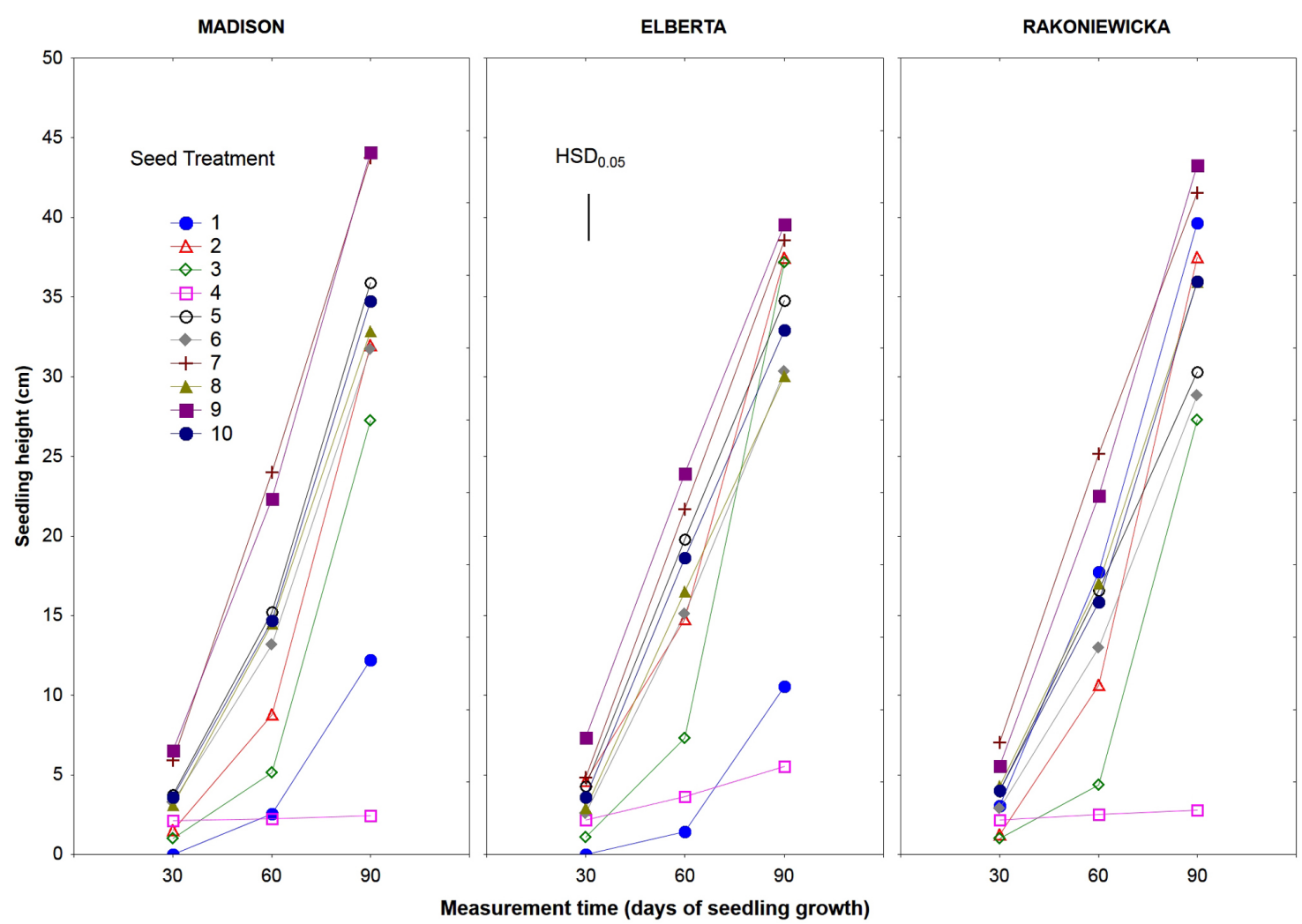

Fig. 5. Seedling growth of three peach genotypes depending on the seed treatment. Means averaged over three years of the experiment. $H S D_{0.05}$ - honestly significant difference calculated according to the Tukey procedure at $\mathrm{p}=0.05$ for comparisons of the treatments at each of the three measurement times

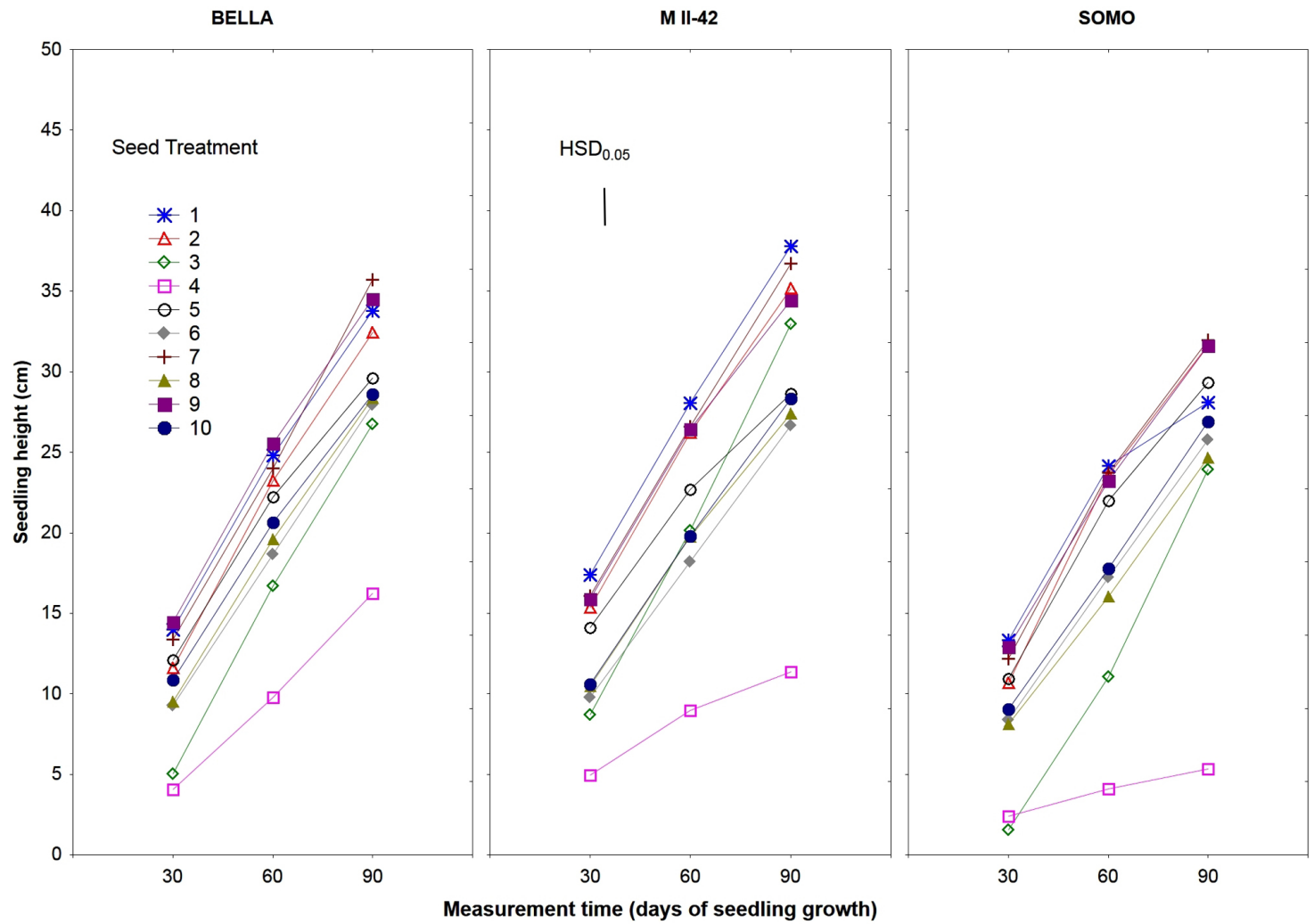

Fig. 6. Seedling growth of three apricot genotypes depending on the seed treatment. Means averaged over three years of the experiment. $H S D_{0.05}$ - honestly significant difference calculated according to the Tukey procedure at $\mathrm{p}=0.05$ for comparisons of the treatments at each of the three measurement times 


\section{Discussion}

The results of our research have shown positive influence of removing the seed coat with endosperm and exposing the extracted embryos to $20^{\circ} \mathrm{C}$ on peach and apricot seed germination. It confirms, therefore, the inhibitory effect of the endocarp and the seed coat on seed germination, which had been previously observed in peach by Martínez-Gómez and Dicenta (2001), and in sour cherry by Jensen and Kristiansen (2009). The inhibitory effect of the endocarp and the seed coat on germination is due to the fact that they form a mechanical barrier to the radicle when the seed is germinating, restrict water from having access to the embryo inside, and hinder the leaching of germination inhibitors (abscisic acid, ABA, among others) from the embryo (Du Toit et al., 1979), and are themselves a source of germination inhibitors (Chen et al., 2007).

Seeds of 'Rakoniewicka' germinated much better than those of 'Madison' and 'Elberta' in the control treatment. But 'Rakoniewicka' is a seed cultivar, whose seeds have long been used in Poland for the production of generative rootstocks for cultivated peach varieties (Jakubowski, 2000; Czynczyk, 2012). It is not surprising, therefore, that the seeds of this cultivar are characterized by a better germination capacity than the seeds of the cultivars 'Madison' and 'Elberta'.

Extracted embryos were not capable of germination at $5^{\circ} \mathrm{C}$. In order to break their dormancy and make them germinate at $5^{\circ} \mathrm{C}$, they had to undergo stratification for at least 45 days for 'Elberta' peach and 40 days for 'Bella' apricot. In their study, Mehanna and Martin (1985) proved that the inability of dormant peach seeds to germinate is caused by the mechanical barrier posed by the seed coat to the growing radicle. In our study, despite the removal of the endocarp and the seed coat with endosperm, the extracted embryos of both peach and apricot did not germinate at $5^{\circ} \mathrm{C}$ within a short period of time. This could be attributed to the presence of inhibitors within them, and consequently lack of germination. In the study by Jensen and Kristiansen (2009), sour cherry embryos that had not been subjected to chilling were able to germinate at $20^{\circ} \mathrm{C}$, while in the study by Martínez-Gómez and Dicenta (2001) peach embryos germinated within one week at $25-30^{\circ} \mathrm{C}$. Also in our study, embryos of the peach and apricot cultivars, both non-chilled and those extracted from seeds stratified for 30 days, germinated only after having been subjected to a temperature of $20^{\circ} \mathrm{C}$. However, the germination percentage of non-chilled embryos was always lower than that of the chilled ones.

After 30 days of stratification and 5 days at $20^{\circ} \mathrm{C}$, it was observed more peach embryos with shortened cotyledons had germinated than embryos with the cotyledons left intact. Undoubtedly, the embryos were still dormant after 30 days of stratification and the inhibitors contained in them had not yet decomposed under the influence of chilling. Research by Chen et al. (2007) had shown that the abscisic acid content in embryos decreased during stratification. In our study, the inhibitors contained in them had been partially removed with the cut-off part of the cotyledons. This could explain why, after 5 days at $20^{\circ} \mathrm{C}$, more of the embryos with shortened cotyledons had germinated in comparison with the embryos with the cotyledons left intact. Also in the study by Jensen and Kristiansen (2009), a higher germination percentage was obtained with dormant sour cherry embryos that had had a portion of their cotyledons removed compared to embryos with whole cotyledons.

The number of germinated embryos increased with the duration of stratification of the seeds from which the embryos had been extracted. This is in agreement with the known fact that during stratification the concentration of germination inhibitors contained in the embryo decreases (Chen et al., 2007). That is why the embryos that had been stratified for a longer time began to germinate sooner after having been placed at a higher temperature.

The results show that the seedlings obtained from embryos with whole cotyledons, extracted from seeds stratified for 60 or 90 days, were taller than the seedlings obtained from embryos exposed to chilling for 30 days. The weakest growth was shown by seedlings obtained from non-stratified seeds. This means that the inhibitors, contained in the embryos, whose content decreases during stratification, have an inhibitory effect on the growth of seedlings obtained from them. In the study by Martínez-Gómez and Dicenta (2001), peach seedlings did not show stunted (rosette) growth if the seeds had been stratified for at least four weeks at $7^{\circ} \mathrm{C}$. However, those seedlings were significantly shorter than those obtained from seeds stratified for 5-14 weeks. Our study produced similar results. The seedlings obtained from seeds stratified for 30 days did not exhibit stunted growth but were shorter than the seedlings obtained from seeds stratified for 60 or 90 days.

In spite of non-stratified embryos germinating, the seedlings obtained from them did not grow normally, contrary to what had been found by Flemion (1965) for peach and Jensen and Kristiansen (2009) for sour cherry. In our studies, the seedlings obtained from non-stratified embryos had severely shortened internodes and exhibited stunted growth. The study by Tang et al. (2000) suggests that the concentration of inhibitors in the distal parts of the cotyledons of sour cherry embryos is higher than at the proximal parts. It seems therefore likely that if a larger portion 
of the cotyledons had been cut off, thus causing the removal of a large amount of the inhibitors contained in them, the seedlings would have proceeded to grow normally.

As the results of our study show, the seedlings obtained from embryos with shortened cotyledons did not grow well compared to the seedlings obtained from embryos with the cotyledons left intact and stratified for the same length of time. It was most evident in the first month of the seedling growth. This was undoubtedly caused by the cutting-off of a portion of the cotyledons, which inevitably involved the removal of some of the nutrients that are used by young developing plants before they become fully autotrophic.

\section{Conclusions}

The results of our studies have shown the suitability of the combination of stratification with removing seed coat with endosperm for the optimization of peach and apricot seed germination. The best way to obtain good germination of seeds and the growth of young peach seedlings is stratification for a period of 90 days, and then removing their seed coat with endosperm and exposing the extracted whole embryos (without shortening cotyledons) to $20^{\circ} \mathrm{C}$. The combination of these treatments makes it possible to obtain a higher number of germinated seeds, as well as earlier and more concentrated in time germination than traditional stratification in constant cold. Similar results were obtained for apricot seeds, but in this case 60 days of stratification is enough.

The applied method makes it possible to obtain, after two or three months of stratification, normally growing peach and apricot seedlings. The method also makes it possible to obtain a greater number of seedlings, shorten the breeding cycle, and thus increase the efficiency of breeding of these species.

\section{Acknowledgements}

The study was financed by the Polish Ministry of Science and Higher Education [Statutory Research, Project No. 1.1.1]. We thank Mr. Mieczysław Paszt for making valuable suggestions for improving the manuscript.

\section{References}

Chen SY, Chien ChT, Chung JD, Yang YS \& Kuo SR (2007) Dormancy-break and germination in seeds of Prunus campanulata (Rosaceae): role of covering layers and changes in concentration of abscisic acid and gibberellins. Seed Science Research 17: 21-32. doi:10.1017/S0960258507383190.

Czynczyk A (2012) Szkółkarstwo sadownicze. 3rd ed. PWRiL, Warszawa, Poland.

Du Toit HJ, Jacobs G \& Strydom DK (1979) Role of the various seed parts in peach seed dormancy and initial seedling growth. Journal of American Society for Horticulture Science 104: 490-492.

Dell Inc. (2016) Dell Statistica (data analysis software system), version 13.software.dell.com.

Flemion F (1933) Dwarf seedlings from non-after ripened embryos of Rhodotypos kerrioides. Contributions Boyce Thompson Institute 5: 161-165.

Flemion F (1934) Dwarf seedlings from non-after ripened embryos of peach, apple and hawthorn. Contributions Boyce Thompson Institute 6: 205209.

Flemion F (1965) Ultrastracture of the shoot apices and leaves of normal and physiologically dwarfed peach seedlings. I. Plastid development. Contributions Boyce Thompson Institute 23: 331-344.

Ghayyad M, Kurbysa M \& Napolsy G (2010) Effect of endocarp removal, gibberelline, stratification and sulfuric acid on germination of mahaleb (Prunus mahaleb L.) seeds. American-Eurasian Journal of Agriculture and Environmental Science 9: 163168.

Jakubowski T (2000) Uprawa brzoskwini i nektaryny. Hortpress, Warszawa, Poland.

Jensen M \& Kristiansen K (2009) Removal of distal part of cotyledons or soaking in BAB overcomes embryonic dormancy in sour cherry. Propagation of Ornamental Plants 9: 135-142.

Martínez-Gómez P \& Dicenta F (2001) Mechanisms of dormancy in seeds of peach (Prunus persica (L) Batsch) cv. GF305. Scientia Horticulturae 91: 5158. doi:10.1016/S0304-4238(01)00235-7.

MacNair JN, Sunkara A \& Frobish D (2012) How to analyse seed germination data using statistical time-to-event analysis: non-parametric and semi-parametric methods. Seed Science Research 22: 77-95. doi:10.1017/S0960258511000547.

Mehanna HT \& Martin GC (1985) Effect of seed coat on peach seed germination. Scientia Horticulturae 25: 247-254. doi:10.1016/0304-4238(85)901220.

Michalska S (1982) Embryonal dormancy and induction of secondary dormancy in seed of mazzard cherry (Prunus avium L.). Arboretum Kórnickie 27: 311-332.

San B, Yildirim AN \& Yildirim F (2014) An in vitro germination technique for some stone fruit species: the embryo isolated from cotyledons successfully germinated without cold pre-treatment of seeds. HortScience 49: 294-296.

Seliga S \& Żurawicz E (2011) Wpływ warunków stratyfikacji na kiełkowanie nasion wiśni (Prunus 
cerasus L.). Zeszyty Naukowe Instytutu Sadownictwa i Kwiaciarstwa im. Szczepana Pieniążka 19: 5-14.

Suszka B (1964) Ciepło-chłodna stratyfikacja nasion uprawnych odmian śliw, wiśni i czereśni. Arboretum Kórnickie 9: 237-261.

Suszka B (1967) Studia nad spoczynkiem i kiełkowaniem nasion różnych gatunków z rodzaju Prunus L. Arboretum Kórnickie 12: 221-282.

Szymajda M, Żurawicz E \& Sitarek M (2011) Kiełkowanie nasion nowych genotypów brzoskwini (Prunus persica L.). Zeszyty Naukowe Instytutu Sadownictwa i Kwiaciarstwa im. Szczepana Pieniążka 19: 15-24.

Szymajda M, Pruski K, Żurawicz E \& Sitarek M (2013) Suitability of selected seed genotypes of Prunus armeniaca L. for harvesting seeds for the production of generative rootstock for apricot cul- tivars. Journal of Agricultural Science 5: 222-232. doi:10.5539/jas.v5n9p222.

Szymajda M \& Żurawicz E (2014) Seed genotypes for harvesting seeds in the production of generative rootstocks for peach cultivars. Horticultural Science (Prague) 41: 160-166. doi:10.17221/86/2014-HORTSCI.

Tang H, Ren Z \& Krczal G (2000) Somatic embryogenesis and organogenesis from immature embryo cotyledons of three sour cherry cultivars (Prunus cerasus L.). Scientia Horticulturae 83: 109-126. doi:10.1016/S0304-4238(99)00073-4.

Therneau TM \& Grambsch PM (2000) Modeling survival data: extending the Cox model. Springer Verlag, New York.

Zielinski QB (1958) Some factors affecting seed germination in sweet cherries. Proceedings American Society Horticultural Science 72: 123-128. 